Article

\title{
Loss of Function of OsARG Resulted in Pepper-Shaped Husk in Indica Rice
}

\author{
Yan Zheng ${ }^{1,2, *}$, Mjomba Fredrick Mwamburi ${ }^{1,2}$, Huaqing Liu ${ }^{3}$ and Feng Wang ${ }^{3}$ \\ 1 College of Life Sciences, Fujian Agriculture and Forestry University, Fuzhou 350002, China; \\ fmjomba@tum.ac.ke \\ 2 Fujian Key laboratory of Crop Breeding by Design, Fujian Agriculture and Forestry University, \\ Fuzhou 350002, China \\ 3 Institute of Biotechnology, Fujian Academy of Agricultural Sciences, Fuzhou 350003, China; \\ lhq@fjage.org (H.L.); wf@fjage.org (F.W.) \\ * Correspondence: zhengyan@fafu.edu.cn; Tel.: +86-591-8378-9176
}

Citation: Zheng, Y.; Mwamburi, M.F.; Liu, H.; Wang, F. Loss of Function of OsARG Resulted in Pepper-Shaped Husk in Indica Rice. Life 2021, 11, 523. https://doi.org/10.3390/life11060523

Academic Editors: Anja Forche and Kousuke Hanada

Received: 12 April 2021

Accepted: 21 May 2021

Published: 3 June 2021

Publisher's Note: MDPI stays neutral with regard to jurisdictional claims in published maps and institutional affiliations.

Copyright: (c) 2021 by the authors. Licensee MDPI, Basel, Switzerland. This article is an open access article distributed under the terms and conditions of the Creative Commons Attribution (CC BY) license (https:// creativecommons.org/licenses/by/ $4.0 /)$.

\begin{abstract}
Grain shape is one of the most important and complex traits determining the grain yield in rice. In this study, we discovered two rice mutants with defective shape spikelets, designated as psh11/2 (pepper-shaped husk 1-1/2), which were both isolated from the tissue-culture-regenerated plants of indica cultivar Minghui 86. The two mutants showed the same mutant phenotypes, containing pepper-shaped spikelets; shorter, smaller and compact panicles; very low seed-setting rate; high percentage of split grains; and lower grain width. Genetic analysis indicated that the mutant phenotypes were controlled by a recessive gene. Gene mapping indicated that the target gene PSH1 was located on the short arm of chromosome 4. Sequencing analysis revealed that the two mutants each had a different nonsense mutation in OsARG, confirming that the target gene is OsARG. Compared with the previously reported OsARG mutant $n g l f-1$, psh1-1/2 possessed some distinct mutant phenotypes, probably because of the influence of different genetic background, suggesting that OsARG may function differently under different genetic backgrounds.
\end{abstract}

Keywords: OsARG; loss-of-function mutation; pepper-like husk; indica rice

\section{Introduction}

Rice is one of the most important food crops for more than half of the global population. Breeding ideal superior rice cultivars with improved grain shape and other agronomic traits, such as nutritional value, disease resistance, and stress tolerance, has been the goal of rice breeders for a long time. Grain shape and grain size are important traits, which influence the grain yield in rice. They are comprehensive and quantitatively inherited, characterized by a combination of grain length, grain width, grain length-to-width ratio, and grain thickness [1].

In past decades, many genes and quantitative trait loci (QTLs) for grain shape and grain size have been identified and cloned in rice [1-4]. GS3, which encodes a transmembrane protein consisting of four putative domains, was the first cloned QTL controlling grain length [5]. qGL3, encoding a putative protein phosphatase with a Kelch-like repeat domain, also regulates grain length [6]. GW2 [7], GW5/qSW5 [8,9], GS5 [10], and GW8 [11] were found as regulators of rice grain width. It has been also found that genes affecting plant hormone biosynthesis and signal transduction can also regulate grain size in rice. Some dwarf genes, like D1/RGA1 involved in the gibberellin pathway [12], and D2 [13] and D11 [14] involved in brassinosteroid (BR) biosynthesis, can also regulate the grain size of rice. Besides, some genes involved in panicle development in rice, such as SP1 [15], qPE9-1 [16], EP2 [17], DEP2 [18], and DEP3 [19], can affect grain size or shape, too. These observations suggest that the regulation of grain shape and grain size are complicated processes controlled by a number of genes. 
Flower appearance is an important character, which influences the grain shape and yield of rice profoundly. Lemma and palea are the outermost layers of rice seeds, which are the unique organs found only in Poaceae, responsible for protecting the florets and grains from pathogens and herbivory, and supplying carbon and nitrogen for the development of kernels [20]. Therefore, it is important for rice to establish the intact lemma and palea morphology. Some researchers have focused their study on the lemma and palea development, and a number of genes have been characterized. It has been found that rice palea might be derived from the fusion of MRP (marginal region of palea) and BOP (body of palea) [21]. MRP is smooth and light-colored, while BOP is instead populated with silicified cells bearing trichomes [22]. They are controlled in different ways. MFO1/MADS6, which is a member of AGL6 clade of MADS-box genes, and CFO1/MADS32 confer vital functions in the regulation of MRP identity, but not BOP identity $[23,24]$. However, $D E-$ PRESSED PALEA 1 (DP1) and OSMADS15 might be involved in the regulation of BOP identity [25]. REP1, encoding a CYC-like TCP transcription factor and hypothesized to be the downstream of the DP1 gene, and PAL1 can promote the growth of BOP and suppress the differentiation of MRP [26,27]. LHS1/OsAMDS1 has a redundant role with MFO1 in palea identity specification by promoting MRP development $[25,28]$. Besides these genes specific effects on palea development, there are many other genes conferring both palea and lemma development, such as OPB [29], DH1 [30], SHO1 [31], SHL2 [32], SHL4 [32], WAF1 [33], TH1 [34], and BH1 [35]. Taken together, these studies suggest that palea and lemma development is a complicated process regulated by various genes.

Apart from grain characteristics, spikelet fertility is one of the critical determinants of rice grain yield. For a long time, most studies have mainly focused on male or female sterility in which plants are extremely sterile. However, low fertility is a complex phenomenon and limited knowledge of its molecular mechanism is known. The spikelet fertility is developmentally regulated by the interaction of genetic factors and environmental conditions [36]. Many defects during growth, especially under environmental stress, and developmental defects in flower structure, pollen viability, anther dehiscence, flower opening, and so on, can cause low fertility in rice [36]. Li et al. [37] reported that POLLEN TUBE BLOCKED 1 (PTB1) can positively regulate the rice seed-setting rate by controlling pollen tube growth. The opening of rice flowers in the early morning helps rice to avoid sterility caused by heat stress at anthesis [38]. Lodicule is an important organ for rice because it forces the flower open through its rapid swelling [39]. Lodicule swelling is promoted by high temperature $\left(35-45^{\circ} \mathrm{C}\right.$ ) and can be induced by carbon dioxide [40]. Zeng et al. [41] reported that exogenous methyl jasmonate (MeJA), a plant hormone, can induce the floret to open through its causing swelling of lodicules by stimulating the expansion of cells. THIS1, encoding a class III lipase, plays a fundamental role in regulating branch and spikelet fertility through regulating pollen maturation, anther dehiscence, and flower opening [36]. In summary, spikelet fertility is a complex trait regulated by various genes and needs to be studied more.

In this study, we isolated and characterized two independent mutants, psh1-1/2, which exhibited pepper-shaped husks with defective palea and very low spikelet fertility. We applied a bulked segregant analysis by the whole genome resequencing (BSA-seq) method to map and clone the candidate gene, and found that the mutation of gene OsARG was the cause of the mutant phenotype. Compared with the published mutant nglf-1 [42], psh1-1/2 possessed different mutation sites and showed some different phenotypes. This work allowed us to further uncover the function of OsARG in regulating flower shape and spikelet fertility. 


\section{Materials and Methods}

\subsection{Plant Materials and Phenotype Observation}

The rice $p s h 1$ mutant was obtained from the progeny of tissue culture of the rice (Oryza sativa L. ssp. indica) cultivar Minghui 86 (MH86). An $\mathrm{F}_{2}$ population was constructed by crossing psh1 ( $(+)$ with an indica cultivar 93-11 ( $\left.\sigma^{7}\right)$, followed by selfing $F_{1}$ individuals. All rice plants were grown in a paddy field under standard growth conditions in Fuzhou city, China. At the ripening stage, plant height, tiller number, panicle length, spikelet number per panicle, number of primary and secondary branches, seed-setting rate, grain length, grain width, and 1000-grain weight were investigated. Student's $t$-test was performed in the statistical analysis of each trait.

\subsection{Pollen Viability Assay}

To determine the pollen viability of $p s h 1$, anthers were collected from a spikelet at the heading stage and moved onto the glass slide. After the anthers were broken, pollens were stained with $\mathrm{I}_{2}$-KI staining buffer consisting of $1 \% \mathrm{I}_{2}$ and $3 \% \mathrm{KI}$ at room temperature. Then, 20-30 min later, the pollen grains were observed using a light microscope and photographed. MH86 was used as control.

\subsection{Mapping of PSH1 Using BSA-seq Method}

Leaves of 20 mutant plants (M-pool) and 20 wild-type plants (W-pool) were collected from the $\mathrm{F}_{2}$ population and bulked, respectively, for DNA extraction using the CTAB method [43]. Two paired-end DNA-sequencing libraries with an average insert size of $400 \mathrm{bp}$ were constructed for the two pools using the Illumina TruSeq DNA LT kit (ID: FC-121-2001) according to the manufacturer's instructions (Illumina, San Diego, CA, USA). Each library was sequenced on an Illumina HiSeq 2500, generating a total of $4.6 \mathrm{~Gb}$ data, representing an average of $12 \times$ coverage of the rice genome. The two parents, MH86 and 93-11, were used as control, and had been sequenced by Fujian Academy of Agricultural Sciences at an average depth of $50 \times$ and $30 \times$, respectively (data unpublished). The alignment and variant calling were performed as described [44]. The biquadratic of average allele frequency difference between the two pools (denoted as $\mathrm{AFD}^{4}$ ) was calculated to detect the target gene PSH1. The highest peak of AFD ${ }^{4}$ was considered to be the target gene region.

\subsection{Fine Mapping of PSH1}

One hundred mutant plants were selected from the $\mathrm{F}_{2}$ population. DNA was extracted from the fresh leaves of each individual and the two parents. InDel and SNP markers were developed in the target region according to the genomic sequence data of MH86 and 93-11 and used to genotype the $\mathrm{F}_{2}$ plants. Primers were designed using Primer 3 (https:/ /bioinfo.ut.ee/primer3-0.4.0/ (accessed on 24 May 2021)) and synthesized by Shanghai Sangon Biological Engineering \& Technology Company (Shanghai, China). PCR was performed in a $15 \mu \mathrm{L}$ reaction mixture containing 20-50 ng genomic DNA, $200 \mu \mathrm{M}$ of each dNTP, $1 \times$ PCR buffer ( $10 \mathrm{mM}$ Tris- $\mathrm{HCl}, \mathrm{pH} 8.4,50 \mathrm{mM} \mathrm{KCl}, 1.5 \mathrm{mM} \mathrm{MgCl}_{2}$ ), $0.5 \mu \mathrm{M}$ each of forward and reverse primers, and $1 \mathrm{U}$ Taq polymerase. All reactions were run with a routing PCR program: 4 min at $94{ }^{\circ} \mathrm{C}, 30$ cycles of $30 \mathrm{~s}$ at $94{ }^{\circ} \mathrm{C}, 30 \mathrm{~s}$ at $58^{\circ} \mathrm{C}$, and $1 \mathrm{~min}$ at $72{ }^{\circ} \mathrm{C}$; and $5 \mathrm{~min}$ at $72{ }^{\circ} \mathrm{C}$ for final extension. PCR products were separated using $6 \%$ non-denaturing PAGE ( $300 \mathrm{~V}, 2 \mathrm{~h}$ ) and stained with silver following the method of $\mathrm{Xu}$ et al. [45] with minor modifications. Linkage analysis was performed using Mapmaker EXP 3.0 [46] between the molecular markers and the PSH1 locus. The Kosambi mapping function was used to convert recombination rate into map distance. Markers were linked with an LOD threshold of 3.0. 


\section{Results}

\section{1. psh1 Mutant Produces Pepper-Shaped Spikelet}

The phenotype of mutant $p s h 1$ was examined at various stages of growth and development. During vegetative growth, $p s h 1$ displayed a similar phenotype to MH86, with no apparent morphological changes. Their plant height and tiller number were similar (Table 1). At the heading stage, psh1 produced flowers at the same time as MH86. The plant architecture of $p s h 1$ was slightly compact compared with that of MH86 (Figure 1A). The panicle of $p s h 1$ was $~ 20 \%$ shorter and more compact than MH86 (Table 1). Unlike MH86, the panicle of $p s h 1$ was partially enclosed by the leaf sheath (Figure 1B). However, the numbers of primary and secondary branches displayed no difference between $p$ sh 1 and MH86 (Table 1). The spikelet of $p s h 1$ showed a pepper-like shape with a slightly larger length but smaller width compared to that of MH86 (Figure 1C; Table 1). As shown in Table 1, the spikelet number per panicle of psh1 was less than that of MH86, and the seed-setting rate of $p \operatorname{sh} 1(5.8 \%)$ was remarkably less than that of wild type (85.2\%).

Table 1. Phenotypic analysis of WT (Minghui 86) and psh1.

\begin{tabular}{ccc}
\hline Trait & Minghui 86 & psh1 \\
\hline Plant Height $(\mathrm{cm})$ & $11.6 \pm 0.91$ & $11.2 \pm 0.95$ \\
Tiller Number & $7.6 \pm 1.71$ & $6.1 \pm 3.07$ \\
Panicle Length $(\mathrm{cm})$ & $3.0 \pm 0.13$ & $2.5 \pm 0.19^{*}$ \\
Spikelet Number per Panicle & $199.7 \pm 21.28$ & $181.9 \pm 30.03^{*}$ \\
Primary Branch Number & $12.3 \pm 0.95$ & $11.9 \pm 1.45$ \\
Secondary Branch Number & $48.9 \pm 7.31$ & $46.0 \pm 6.57$ \\
Seed Setting Rate (\%) & $85.2 \pm 4.98$ & $5.8 \pm 7.28^{* *}$ \\
Grain Length (mm) & $9.4 \pm 0.66$ & $8.7 \pm 0.48^{*}$ \\
Grain Width (mm) & $2.8 \pm 0.42$ & $2.0 \pm 0.08^{*}$ \\
1000-Grain Weight (g) & $28.7 \pm 0.66$ & $15.0 \pm 1.19^{* *}$ \\
\hline
\end{tabular}

Note: Values are mean \pm SD. Asterisks indicate significant differences to wild type (MH86) at $p<0.05\left(^{*}\right)$ or $\left.p<0.01{ }^{* *}\right)$ according to $t$-test $(n=10)$.
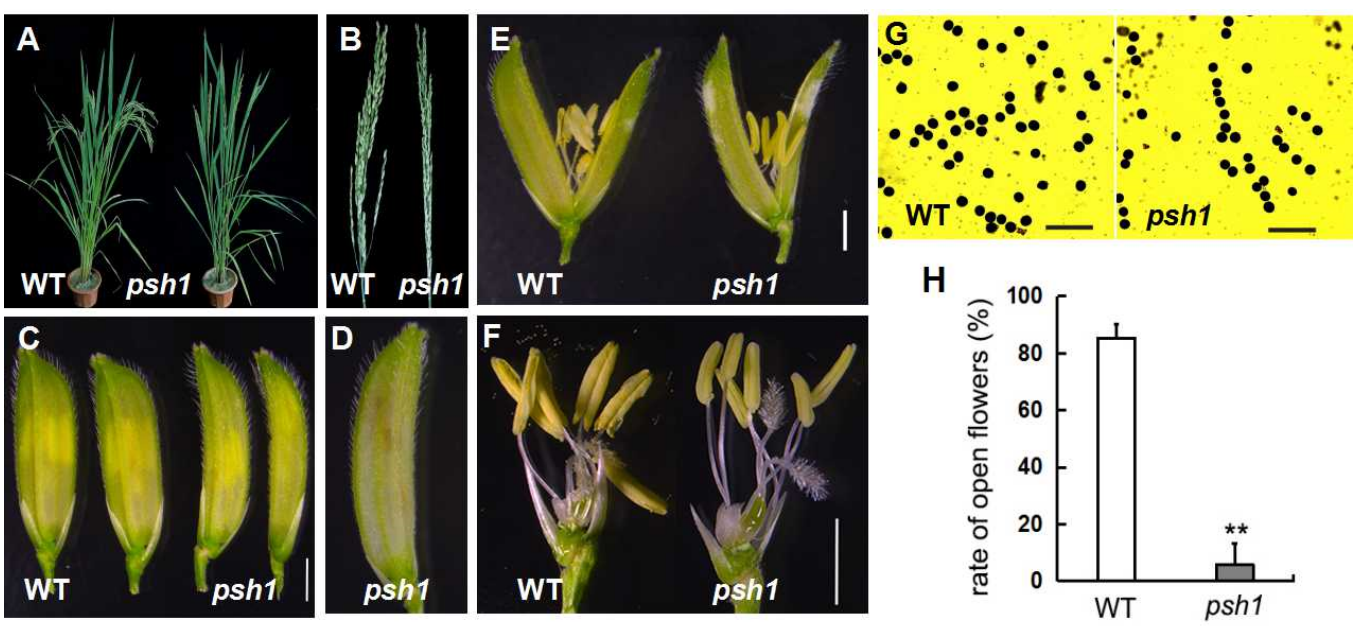

Figure 1. Phenotype of $p s h 1$ mutant. (A) Phenotype of WT (MH86) and $p s h 1$ plants at the heading stage. (B) Panicles of WT and $p s h 1$ at the heading stage. (C) Spikelets of WT and psh1. Bar $=2 \mathrm{~mm}$. (D) A spikelet of psh1 showing brown inside. (E) Opened spikelets of WT and psh1. Bar $=2 \mathrm{~mm}$. (F) Spikelets of WT and psh1 with lemma and palea removed. Bar $=2 \mathrm{~mm}$. (G) Pollen viability test using potassium iodide staining. Bar $=200 \mu \mathrm{m}$. (H) Rate of open flowers of WT and psh1. Asterisks indicate significant differences to wild type $(\mathrm{MH86})$ at $p<0.01\left({ }^{* *}\right)$ according to $t$-test $(n=10)$. 
In order to explain the reduced fertility of $p s h 1$, we examined the internal structure of the $p s h 1$ flower and found that there were no apparent distinguished changes compared to the wild type (Figure 1E,F). Pollen viability analysis showed that the size, morphology, and staining pattern of $p s h 1$ pollen grains were similar to those of wild type (Figure 1G). However, the opening and closing of the $p s h 1$ flower was abnormal. There were many more unopened flowers in the inflorescence of $p s h 1$ than in the wild-type inflorescence. Only a small percentage $(6.55 \%)$ of flowers eventually opened in $p$ sh 1 , compared to $84.65 \%$ in wild type under the same condition (Figure $1 \mathrm{H}$ ). As a result, the anthers in unopened flowers became brown and inactive (Figure 1D). These observations suggested that the reduced fertility of $p s h 1$ is not caused by floral structure and pollen grain activity, but by the behavior of the flower opening, at least in part.

\subsection{Abnormal Grain Size and Grain Shape of psh1}

At the mature stage, the grain size and grain shape of $p s h 1$ were analyzed. The seeds produced by $p s h 1$ appeared smaller than those produced by wild type, and many of them $(62.75 \pm 0.05 \%)$ had split glumes (Figure 2A). The grain length $(8.7 \pm 0.48 \mathrm{~mm})$ and width $(2.0 \pm 0.08 \mathrm{~mm})$ of $p$ sh 1 were significantly less than those of wild type (Table 1; Figure 2C,D). When lemma and palea were removed, the inside rice of $p s h 1$ was much smaller than that of wild type and showed a pepper shape (Figure 2B). As a result, the 1000-grain weight of psh1 was reduced a lot compared with that of the wild type (Table 1; Figure 2F).
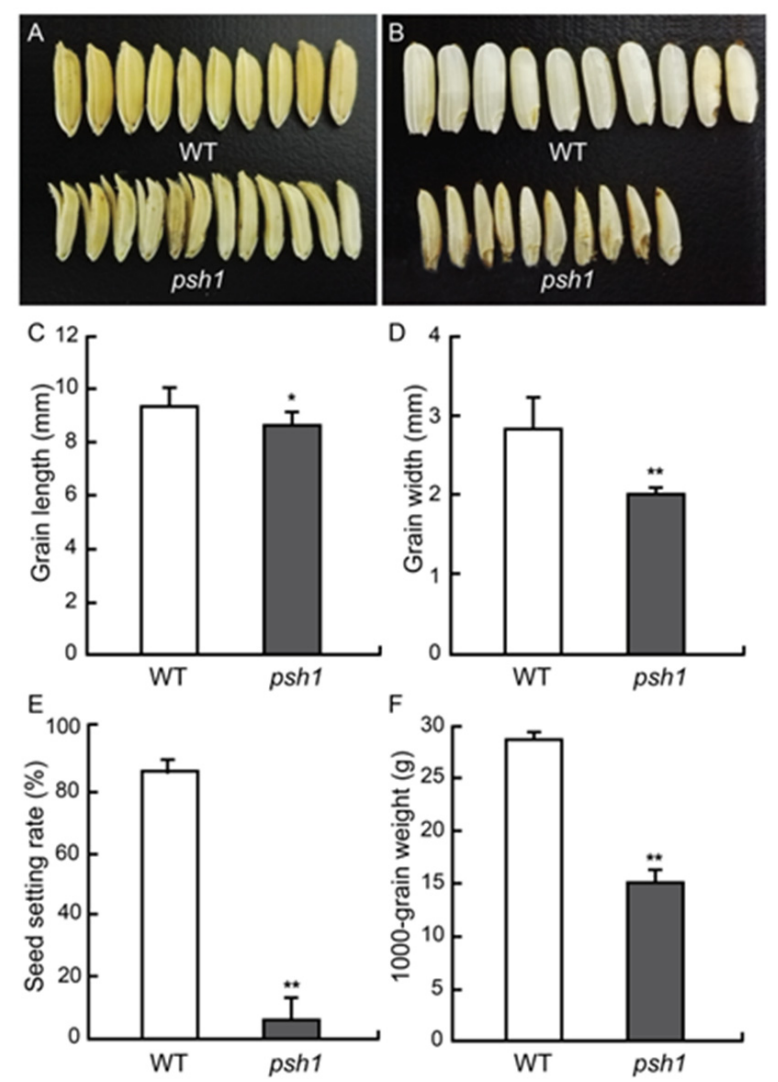

Figure 2. Comparison of mature grains. (A) Seeds of WT and psh1. (B) Dehulled grains of WT and psh1. (C) Grain length. (D) Grain Width. (E) Seed-setting rate. (F) Thousand kernel weight. Asterisks indicate significant differences at $p<0.05\left(^{*}\right)$ or $\left.p<0.01{ }^{* *}\right)$ according to $t$-test. Error bar represents SD. $n=10$. 


\subsection{Genetic Analysis of psh1}

$\mathrm{F}_{1}$ plants of the cross between mutant psh1 and wild type 93-11 showed the wild-type phenotype, including spikelet shape and fertility, suggesting that the mutant allele of PSH1 was recessive. In $\mathrm{F}_{2}, 126$ of 461 plants showed pepper-shaped seeds and low fertility. The segregation of wild-type and mutant plants fitted the ratio of $3: 1\left(\chi^{2}=1.33, P=0.248\right)$. This result indicated that the mutant phenotype of pepper-shaped husk and low fertility was controlled by a single recessive gene.

\subsection{Mapping of PSH1}

The BSA-seq approach was used to map the PSH1 gene based on the $\mathrm{F}_{2}$ population. A total of 670,753 variants of DNA sequence (including 591,231 SNPs, 67,799 short InDels and 11,723 others) were identified and selected as markers for mapping PSH1. The highest peak of $\mathrm{AFD}^{4}$ was found at the beginning of the short arm of chromosome 4, covering a region of $\sim 3 \mathrm{Mb}$ (from $0 \mathrm{Mb}$ to $3.0 \mathrm{Mb}$ in the physical map), with the climax at $\sim 0.3 \mathrm{Mb}$ (Figure 3), which suggested that PSH1 is likely located in this region.

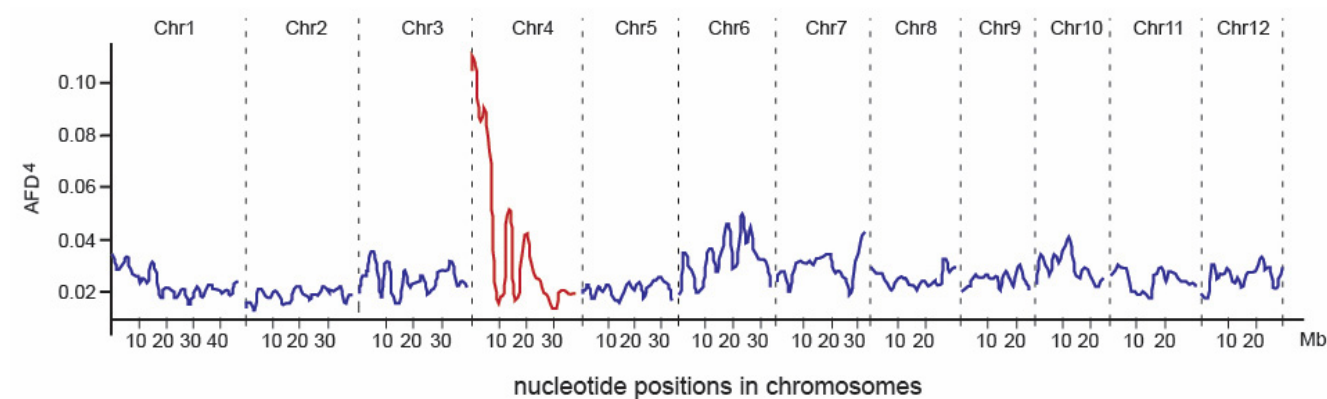

Figure 3. AFD 4 profile across the rice genome. The highest $\mathrm{AFD}^{4}$ peak was detected on chromosome 4 .

To fine map PSH1, a set of InDel markers were developed in the target $3 \mathrm{Mb}$ region of chromosome 4 using the information from the sequencing data. One hundred plants with pepper-shaped husks and low fertility from the $\mathrm{F}_{2}$ population were genotyped with the InDel markers. After linkage analysis, PSH1 was primarily mapped in a region between the start of chromosome 4 and marker LP-03, with a distance of $2.5 \mathrm{cM}$ from LP-03 (Figure 4). Using markers developed in this region, $P S H 1$ was further mapped to a $4.0 \mathrm{cM}$ or $218 \mathrm{~kb}$ interval delimited by markers LP-17 and LP-20 (Figure 4).

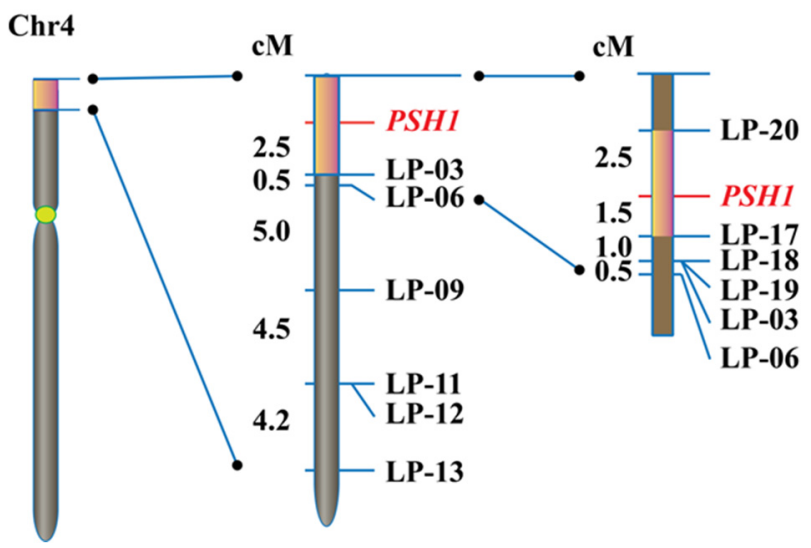

Figure 4. Fine mapping of PSH1. The orange boxes indicate the regions harboring the target gene PSH1 on chromosome 4 determined by BSA-seq (left), primary mapping (middle), and fine mapping (right), respectively. The names of InDel markers and the target gene are shown on the right of the chromosome. The genetic distance $(\mathrm{cM})$ between adjacent loci are shown on the left of the chromosome. 


\subsection{Identification of PSH1}

To identify the candidate gene of PSH1, the open reading frames (ORFs) in the region between LP-17 and LP-20 were analyzed. A total of 31 putative ORFs were found (Figure 5). We examined the target mutation site of $p s h 1$ by comparing the assembled genomic sequences of the 31 ORFs in the W-pool, M-pool, MH86, and 93-11, based on the expectation that the M-pool would only contain the mutant allele, while the $\mathrm{W}$-pool would contain the mutant allele and the wild-type (MH85 and 93-11) allele simultaneously. Using this method, a nucleotide substitution ( $\mathrm{G}$ to $\mathrm{T})$ mutation was found at the fourth exon of gene LOC_Os04g01590, which resulted in premature termination of the protein encoded by the gene (Figure 5). To verify the mutation, we developed a pair of primers (Loc590-2F: TCCAGTTGTTAGGGCTGTGT and Loc-590-2R: GCCTCCTAGCATAACCTCCT) flanking the mutation site ( $\mathrm{G}$ to $\mathrm{T}$ ) to amplify the sequence in 40 mutant plants from the $F_{2}$ population. After sequencing the amplified sequences, it was found that 31 mutant plants had the expected nucleotide substitution (Figure 6A). However, the other 9 mutant plants did not contain the mutation. By rechecking the sequence of LOC_Os04g01590, we found that there was another nucleotide substitution (G to T) occurred in the fifth exon of LOC_Os04g01590, which also led to a premature stop codon (Figure 6B). However, the M-pool contained the mutant allele of this site as well as the wild-type allele, and the mutant allele actually only accounted for a small proportion in the M-pool. That is why it was ignored initially. Using a pair of primers (Loc-590-5F: GTAGGATCCTCTTCGGCCAT and Loc-590-5R: TGTCCAAACAGA GCATCTACG), we verified that the 9 mutant plants did carry the mutant allele. Therefore, there were two mutant alleles of LOC_Os04g01590 in the $F_{2}$ population, but the second mutant allele had a lower frequency. The reason for two mutant alleles existing in the same $\mathrm{F}_{2}$ population might be that the two types of mutants, which could not be distinguished in morphology, were both used as parents to be crossed with 93-11. We designated the first mutant as psh1-1 and the second mutant as psh1-2. The two different mutations of LOC_Os04g01590 causing the same mutant phenotypes confirmed that LOC_Os04g01590 is the candidate gene of PSH1.

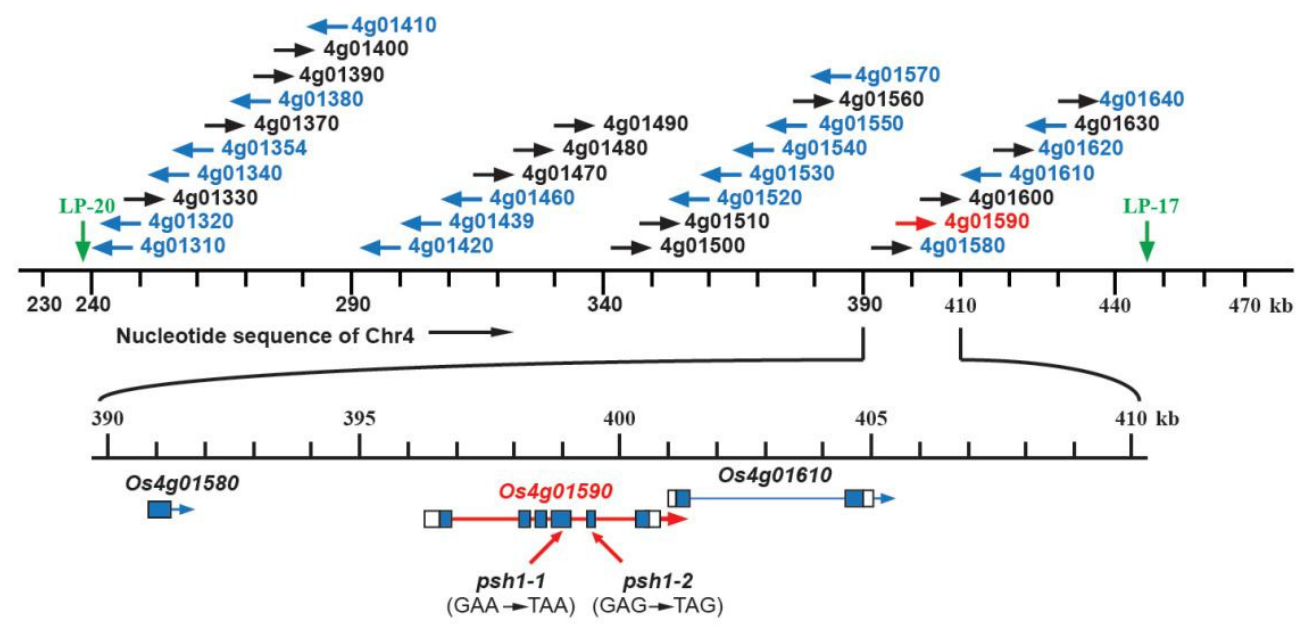

Figure 5. Identification of $p s h 1$ as a nonsense mutant of LOC_Os04g01590. The $218 \mathrm{~kb}$ genomic region between LP-20 and LP-17 contains 31 coding sequences (CDSs). Two mutant alleles were found in LOC_Os04g01590. One contained a substitution of GAA to TAA in the fourth exon, and the other contained a substitution of GAG to TAG in the fifth exon. Both mutations resulted in a premature stop in the CDS. No nucleotide change was found in the remaining 30 CDSs. Black/blue arrows indicate the directions of CDSs opposite to/the same as that of the chromosome 4 nucleotide sequence. The red arrow highlights LOC_Os04g1590 as the candidate gene for PSH1. The exon-intron structures of LOC_Os04g1590 and its two neighboring CDSs are depicted below the chromosome 4 nucleotide sequence. 


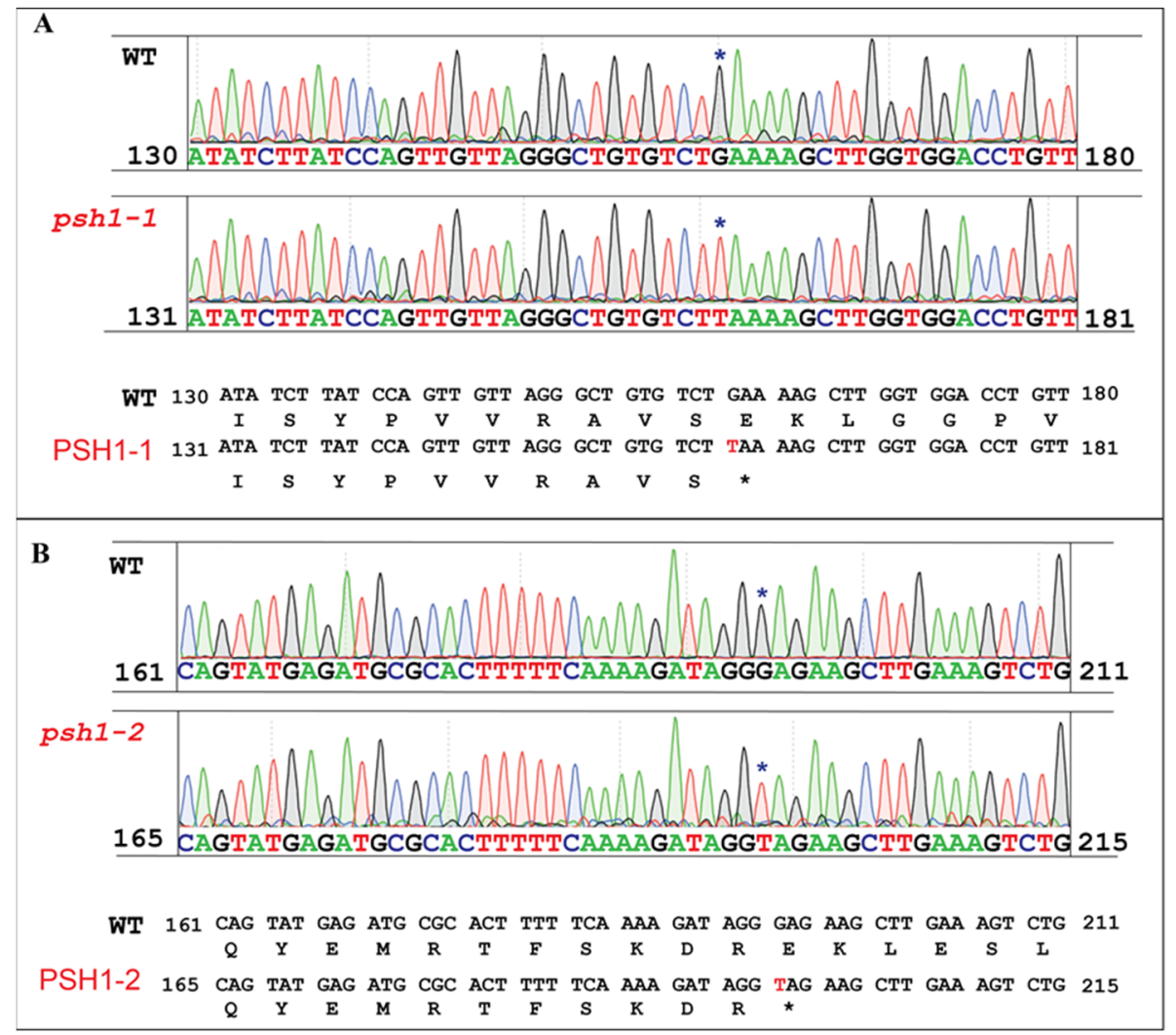

Figure 6. Sequence analysis of $p s h 1$ mutant. Two independent point mutations resulting in stop codons were found in the fourth and the fifth exons of the LOC_Os04g01590, respectively. The two mutant alleles were named $p s h 1-1$ (A) and $p s h 1-2(\mathbf{B})$, respectively. The mutated bases and codons are marked with asterisks.

\subsection{PSH1-1/2 Are New Alleles of OsARG}

The Rice Genome Annotation Project (http:/ / rice.plantbiology.msu.edu/ (accessed on 24 May 2021)) identifies LOC_Os04g01590 as a putative arginase gene. It is a rice ortholog of Arabidopsis ARG gene. OsARG has six exons and encodes a protein of 340 amino acids. OsARG contains one mitochondrial targeting peptide at the N-terminal end, a conserved arginase domain, and two $\mathrm{Mn}^{2+}$ binding (MB) sites (Figure 7). The stop codon mutation in the fourth exon in psh1-1 and that in the fifth exon in psh1-2 resulted in loss of two and one MB site, respectively. They were two new alleles of OsARG. 
A DNA mutation sites

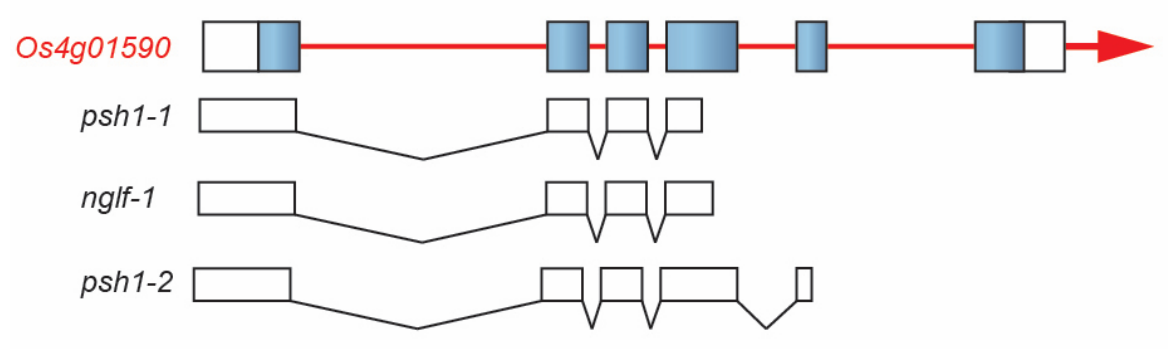

B peptide mutation sites

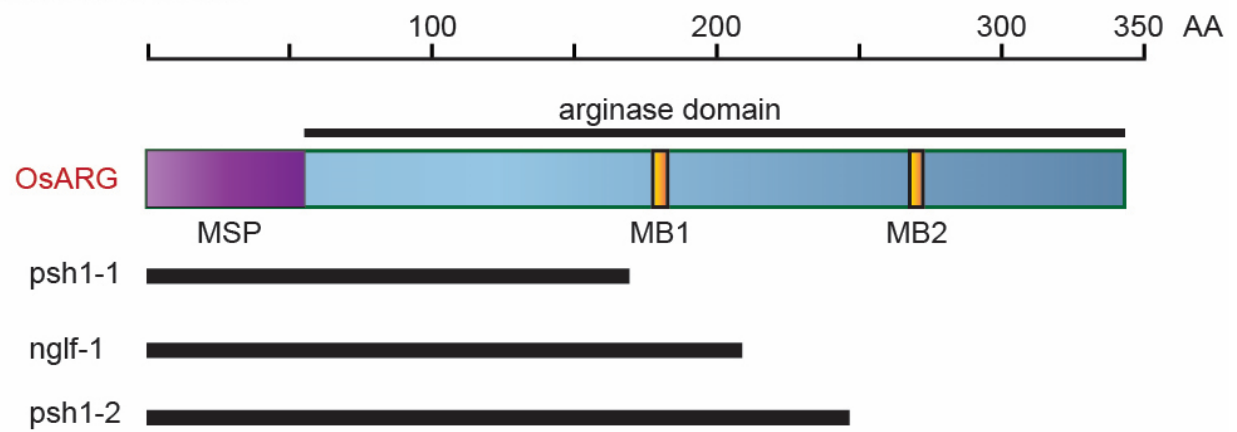

Figure 7. Different mutation sites of OsARG in the mutants psh1-1, psh1-2, and nglf-1. (A) DNA mutation sites of gene LOC_Os04g01590. (B) Peptide mutation sites of OsARG. MSP: mitochondrial signal peptide; $\mathrm{MB}: \mathrm{Mn}^{2+}$ binding site.

\section{Discussion}

In this study, we identified two new mutants of OsARG (psh1-1/2) caused by nonsense mutations, which both resulted in truncated OsARG peptides with one or two MB boxes deleted. Therefore, the function of OsARG must be completely lost in the two mutants. The two mutants had the same phenotype and were indistinguishable in morphology, both showing defective palea, pepper-shaped husks, split glumes, and low seed-setting rates. Our findings suggest that OsARG is an important gene with multiple effects on rice plant development.

A mutant of OsARG named nglf-1 has been reported before [42]. Similar to $p s h 1-1 / 2$, $n g l f-1$ also shows a dramatically low seed-setting rate. However, unlike $p s h 1-1 / 2, n g l f-1$ does not show significant changes in grain shape, except for becoming a little narrower than wild type. As the mutation of OsARG in $n g l f-1$ also results in a truncated peptide with the MB2 deleted, as is the case with psh1-2 (Figure 7), the OsARG function is also completely lost in nglf-1. Therefore, the different mutant phenotypes observed in $p$ sh1$1 / 2$ and nglf- 1 may probably be caused by the difference of genetic background between them. The mutant $p s h 1-1 / 2$ and the $\mathrm{F}_{2}$ population used in this study all had the genetic background of indica rice. In contrast, the genetic background of nglf- 1 is more complicated. The mutant $n g l f-1$ is generated from the anther culture of a tetraploid indica/japonica hybrid H3774. Therefore, nglf-1 is a mixture of indica and japonica background. It is possible that the functionless mutant alleles of OsARG interact with the different genetic background, resulting in different mutant phenotypes. This suggests that OsARG may function differently under different genetic backgrounds.

Flower opening is an important process for seed-setting in rice. Before floret opening, the anthers will begin to dehisce when they reach the top of the floret. At the flowering time, the two lodicules become turgid and force the lemma and palea open. After floret opening, the filaments elongate further, and the remaining pollen grain is released. Then, the floret closes and keeps the empty anthers outside [36]. In spite of the premature termination of OsARG protein, the three mutants can still obtain some seeds. The seed-setting rate of psh1-1/2 is 0.07 times that of wild type, a little lower than that of $n g l f-1$ ( 0.11 times that of wild type). We speculate that the low seed-setting rate of these mutants is caused by the 
defect of the flower opening. In $p$ sh1-1/2, we found that most florets could not open at the flowering time, so that the anthers inside the floret lost activity and became brown. In addition, for the opened florets, many could not close normally after pollinating, so that more than half of the mature seeds showed glume split. To investigate the cause of the unopened florets, we examined the size and structure of lodicules in psh1-1/2, but found no difference from those of wild type (Figure 1F; Figure S1). Therefore, it appears that the abnormal activity of the flower opening and closing in $p$ sh1-1/2 has no relationship with lodicules. Further study is needed to uncover the mechanism.

OsARG is the only gene encoding arginase in rice, which is one of key enzymes in the Arg catabolism pathway [42]. In nglf-1, Arg catabolism is blocked, resulting in nitrogen shortage and the aberrant phenotype in the panicle, which can be partially recovered by exogenous nitrogen. We also performed a similar test on $p$ sh1-1/2. The results showed that when $p s h 1-1 / 2$ was planted under a high exogenous nitrogen concentration condition ( $0.4 \mathrm{~g} \mathrm{~N} / \mathrm{kg}$ soil), the shapes of grain, palea, and lemma in $p s h 1-1 / 2$ were very similar to those of wild type, suggesting that the phenotype of $p s h 1-1 / 2$ was partially recovered by exogenous nitrogen (Figure S2). These results confirmed the function of OsARG and validated the results of Ma et al. [42].

In conclusion, $p s h 1-1 / 2$ are two new mutants of OsARG. They showed some similar mutant phenotypes to those of the reported mutant nglf-1, but also displayed some distinct mutant phenotypes, especially on the shapes of floret and seed, probably because of the influence of the genetic background, suggesting that OsARG may function differently under different genetic backgrounds. The results of this study will help better understand the function of OsARG and provide more information for further study on the growth and development of rice flowers.

Supplementary Materials: The following are available online at https://www.mdpi.com/article/ 10.3390/life11060523/s1, Figure S1: Cross-section of flowers of $p s h 1$ and wild type by resin section, Figure S2: Grain shapes of $p s h 1$ under low and high exogenous nitrogen concentration.

Author Contributions: Conceptualization, Y.Z. and M.F.M.; methodology, Y.Z. and M.F.M.; formal analysis, Y.Z., M.F.M., H.L. and F.W.; investigation, Y.Z. and M.F.M.; writing-original draft preparation, Y.Z. and M.F.M.; writing-review and editing, Y.Z. and M.F.M.; supervision, Y.Z. All authors have read and agreed to the published version of the manuscript.

Funding: This research was funded by Natural Science Foundation of Fujian Province (CN) (2020I0009).

Institutional Review Board Statement: Not applicable.

Informed Consent Statement: Not applicable.

Data Availability Statement: Not applicable.

Acknowledgments: We thank Weiqi Tang and Likun Huang for their help in data analysis.

Conflicts of Interest: The authors declare no conflict of interest.

\section{References}

1. Huang, R.; Jiang, L.; Zheng, J.; Wang, T.; Wang, H.; Huang, Y.; Hong, Z. Genetic bases of rice grain shape: So many genes, so little known. Trends Plant Sci. 2013, 18, 218-226. [CrossRef] [PubMed]

2. Gao, X.; Zhang, X.; Lan, H.; Huang, J.; Wang, J.; Zhang, H. The additive effects of GS3 and qGL3 on rice grain length regulation revealed by genetic and transcriptome comparisons. BMC Plant Biol. 2015, 15, 156. [CrossRef] [PubMed]

3. Zhou, Y.; Miao, J.; Gu, H.; Peng, X.; Leburu, M.; Yuan, F.; Gu, H.; Gao, Y.; Tao, Y.; Zhu, J.; et al. Natural variations in SLG7 regulate grain shape in rice. Genetics 2015, 201, 1591-1599. [CrossRef] [PubMed]

4. Zhao, D.S.; Li, Q.F.; Zhang, C.Q.; Zhang, C.; Yang, Q.Q.; Pan, L.X.; Ren, X.Y.; Lu, J.; Gu, M.H.; Liu, Q.Q. GS9 acts as a transcriptional activator to regulate rice grain shape and appearance quality. Nat. Commun. 2018, 9, 1240. [CrossRef] [PubMed]

5. Fan, C.; Xing, Y.; Mao, H.; Lu, T.; Han, B.; Xu, C.; Li, X.; Zhang, Q. GS3, a major QTL for grain length and weight and minor QTL for grain width and thickness in rice, encodes a putative transmembrane protein. Theor. Appl. Genet. 2006, 112, 1164-1171. [CrossRef] 
6. Zhang, X.; Wang, J.; Huang, J.; Lan, H.; Wang, C.; Yin, C.; Wu, Y.; Tang, H.; Qian, Q.; Li, J.; et al. Rare allele of OsPPKL1 associated with grain length causes extra-large grain and a significant yield increase in rice. Proc. Natl. Acad. Sci. USA 2012, 109, 21534-21539. [CrossRef]

7. Song, X.J.; Huang, W.; Shi, M.; Zhu, M.Z.; Lin, H.X. A QTL for rice grain width and weight encodes a previously unknown RING-type E3 ubiquitin ligase. Nat. Genet. 2007, 39, 623-630. [CrossRef]

8. Shomura, A.; Izawa, T.; Ebana, K.; Ebitani, T.; Kanegae, H.; Konishi, S.; Yano, M. Deletion in a gene associated with grain size increased yields during rice domestication. Nat. Genet. 2008, 40, 1023-1028. [CrossRef]

9. Weng, J.; Gu, S.; Wan, X.; Gao, H.; Guo, T.; Su, N.; Lei, C.; Zhang, X.; Cheng, Z.; Guo, X.; et al. Isolation and initial characterization of GW5, a major QTL associated with rice grain width and weight. Cell Res. 2008, 18, 1199-1209. [CrossRef]

10. Li, Y.; Fan, C.; Xing, Y.; Jiang, Y.; Luo, L.; Sun, L.; Shao, D.; Xu, C.; Li, X.; Xiao, J.; et al. Natural variation in GS5 plays an important role in regulating grain size and yield in rice. Nat. Genet. 2011, 43, 1266-1269. [CrossRef]

11. Wang, S.; Wu, K.; Yuan, Q.; Liu, X.; Liu, Z.; Lin, X.; Zeng, R.; Zhu, H.; Dong, G.; Qian, Q.; et al. Control of grain size, shape and quality by OsSPL16 in rice. Nat. Genet. 2012, 44, 950-954. [CrossRef]

12. Ashikari, M.; Wu, J.; Yano, M.; Sasaki, T.; Yoshimura, A. Rice gibberellin-insensitive dwarf mutant gene Dwarf 1 encodes the alpha-subunit of GTP-binding protein. Proc. Natl. Acad. Sci. USA 1999, 96, 10284-10289. [CrossRef]

13. Hong, Z.; Ueguchi-Tanaka, M.; Umemura, K.; Uozu, S.; Fujioka, S.; Takatsuto, S.; Yoshida, S.; Ashikari, M.; Kitano, H.; Matsuoka, M. A rice brassinosteroid-deficient mutant, ebisu dwarf (d2), is caused by a loss of function of a new member of cytochrome P450. Plant Cell 2003, 15, 2900-2910. [CrossRef]

14. Tanabe, S.; Ashikari, M.; Fujioka, S.; Takatsuto, S.; Yoshida, S.; Yano, M.; Yoshimura, A.; Kitano, H.; Matsuoka, M.; Fujisawa, Y.; et al. A novel cytochrome P450 is implicated in brassinosteroid biosynthesis via the characterization of a rice dwarf mutant, dwarf11, with reduced seed length. Plant Cell 2005, 17, 776-790. [CrossRef]

15. Li, S.; Qian, Q.; Fu, Z.; Zeng, D.; Meng, X.; Kyozuka, J.; Maekawa, M.; Zhu, X.; Zhang, J.; Li, J.; et al. Short panicle1 encodes a putative PTR family transporter and determines rice panicle size. Plant J. 2009, 58, 592-605. [CrossRef]

16. Zhou, Y.; Zhu, J.; Li, Z.; Yi, C.; Liu, J.; Zhang, H.; Tang, S.; Gu, M.; Liang, G. Deletion in a quantitative trait gene qPE9-1 associated with panicle erectness improves plant architecture during rice domestication. Genetics 2009, 183, 315-324. [CrossRef]

17. Zhu, K.; Tang, D.; Yan, C.; Chi, Z.; Yu, H.; Chen, J.; Liang, J.; Gu, M.; Cheng, Z. Erect panicle2 encodes a novel protein that regulates panicle erectness in indica rice. Genetics 2010, 184, 343-350. [CrossRef]

18. Li, F.; Liu, W.; Tang, J.; Cheng, J.; Tong, H.; Hu, B.; Li, C.; Fang, J.; Cheng, M.; Chu, C. Rice dense and erect panicle 2 is essential for determining panicle outgrowth and elongation. Cell Res. 2010, 7, 838-849. [CrossRef]

19. Qiao, Y.; Piao, R.; Shi, J.; Lee, S.I.; Jiang, W.; Kim, B.; Lee, J.; Han, L.; Ma, W.; Koh, H. Fine mapping and candidate gene analysis of dense and erect panicle 3, DEP3, which confers high grain yield in rice (Oryza sativa L.). Theor. Appl. Genet. 2011, 122, 1439-1449. [CrossRef]

20. Abebe, T.; Skadsen, R.W.; Kaeppler, H.F. Cloning and identification of highly expressed genes in barley lemma and palea. Crop Sci. 2004, 44, 942-950. [CrossRef]

21. Yoshida, H.; Nagato, Y. Flower development in rice. J. Exp. Bot. 2011, 62, 4719-4730. [CrossRef]

22. Lombardo, F.; Yoshida, H. Interpreting lemma and palea homologies: A point of view from rice floral mutants. Front. Plant Sci. 2015, 6, 61. [CrossRef]

23. Ohmori, S.; Kimizu, M.; Sugita, M.; Miyao, A.; Hirochika, H.; Uchida, E.; Nagato, Y.; Yoshida, H. MOSAIC FLORAL ORGANS1, an AGL6-like MADS box gene, regulates floral organ identity and meristem fate in rice. Plant Cell 2009, 21, 3008-3025. [CrossRef]

24. Sang, X.; Li, Y.; Luo, Z.; Ren, D.; Fang, L.; Wang, N.; Zhao, F.; Ling, Y.; Yang, Z.; Liu, Y.; et al. CHIMERIC FLORAL ORGANS1, encoding a monocot-specific MADS box protein, regulates floral organ identity in rice. Plant Physiol. 2012, 160, 788-807. [CrossRef]

25. Wang, K.; Tang, D.; Hong, L.; Xu, W.; Huang, J.; Li, M.; Gu, M.; Xue, Y.; Zhu, C. DEP and AFO regulate reproductive habit in rice. PLoS Genet. 2010, 6, e1000818. [CrossRef]

26. Yuan, Z.; Gao, S.; Xue, D.W.; Luo, D.; Li, L.T.; Ding, S.Y.; Yao, X.; Wilson, Z.A.; Qian, Q.; Zhang, D.B. RETARDED PALEA1 controls palea development and floral zygomorphy in rice. Plant Physiol. 2009, 149, 235-244. [CrossRef]

27. Luo, Q.; Zhou, K.; Zhao, X.; Zeng, Q.; Xia, H.; Zhai, W.; Xu, J.; Wu, X.; Yang, H.; Zhu, L. Identification and fine mapping of a mutant gene for palealess spikelet in rice. Planta 2005, 221, 222-230. [CrossRef]

28. Jeon, J.S.; Lee, S.; Nam, J.; Kim, C.; Lee, S.H.; Chung, Y.Y.; Kim, S.R.; Lee, Y.H.; Cho, Y.G.; An, G. Leafy hull sterile1 is a homeotic mutation in a rice MADS box gene affecting rice flower development. Plant Cell 2000, 12, 871-884. [CrossRef]

29. Horigome, A.; Nagasawa, N.; Ikeda, K.; Ito, M.; Itoh, J.; Nagato, Y. Rice open beak is a negative regulator of class 1 knox genes and a positive regulator of class B floral homeotic gene. Plant J. 2009, 58, 724-736. [CrossRef]

30. Li, A.; Zhang, Y.; Wu, X.; Tang, W.; Wu, R.; Dai, Z.; Liu, G.; Zhang, H.; Wu, C.; Chen, G.; et al. DH1, a LOB domain-like protein required for glume formation in rice. Plant Mol. Biol. 2008, 66, 491-502. [CrossRef] [PubMed]

31. Itoh, J.I.; Kitano, H.; Matsuoka, M.; Nagato, Y. SHOOT ORGANIZATION genes regulate shoot apical meristem organization and the pattern of leaf primordium initiation in rice. Plant Cell 2000, 12, 2161-2174. [CrossRef] [PubMed]

32. Nagasaki, H.; Itoh, J.; Hayashi, K.; Hibara, K.; Satoh-Nagasawa, N.; Nosaka, M.; Mukouhata, M.; Ashikari, M.; Kitano, H.; Matsuoka, M.; et al. The small interfering RNA production pathway is required for shoot meristem initiation in rice. Proc. Natl. Acad. Sci. USA 2007, 104, 14867-14871. [CrossRef] [PubMed] 
33. Abe, M.; Yoshikawa, T.; Nosaka, M.; Sakakibara, H.; Sato, Y.; Nagato, Y.; Itoh, J. WAVY LEAF1, an ortholog of Arabidopsis HEN1, regulates shoot development by maintaining microRNA and trans-acting small interfering RNA accumulation in rice. Plant Physiol. 2010, 154, 1335-1346. [CrossRef] [PubMed]

34. Li, X.; Sun, L.; Tan, L.; Liu, F.; Zhu, Z.; Fu, Y.; Sun, X.; Sun, X.; Xie, D.; Sun, C. TH1, a DUF640 domain-like gene controls lemma and palea development in rice. Plant Mol. Biol. 2012, 78, 351-359. [CrossRef]

35. Wei, X.; Zhang, X.; Shao, G.; He, J.; Jiao, G.; Xie, L.; Sheng, Z.; Tang, S.; Hu, P. Fine mapping of BH1, a gene controlling lemma and palea development in rice. Plant Cell Rep. 2013, 32, 1455-1463. [CrossRef]

36. Liu, W.; Zhang, D.; Tang, M.; Li, D.; Zhu, Y.; Zhu, L.; Chen, C. THIS1 is a putative lipase that regulates tillering, plant height, and spikelet fertility in rice. J. Exp. Bot. 2013, 64, 4389-4402. [CrossRef]

37. Li, S.; Li, W.; Huang, B.; Cao, X.; Zhou, X.; Ye, S.; Li, C.; Gao, F.; Zou, T.; Xie, K.; et al. Natural variation in PTB1 regulates rice seed setting rate by controlling pollen tube growth. Nat. Commun. 2013, 4, 2793. [CrossRef]

38. Satake, T.; Yoshida, S. High temperature-induced sterility in indica rices at flowering. Jpn. J. Crop Sci. 1978, 47, 6-17. [CrossRef]

39. Hoshikawa, K. The Growing Rice Plant-An Anatomical Monograph; Nobunkyo Press: Tokyo, Japan, 1989 ; pp. 30-31.

40. Wang, Z.; Gu, Y.J.; Gao, Y.Z. Studies on the mechanism of rice glume-opening: I effect of $\mathrm{CO}_{2}$ on glume-opening. Acta Agron. Sin. 1989, 15, 59-66. (In Chinese)

41. Zeng, X.; Zhou, X.; Zhang, W.; Murofushi, N.; Kitahara, T.; Kamuro, Y. Opening of rice floret in rapid response to methyl jas-monate. J. Plant Growth Regul. 1999, 18, 153-158. [CrossRef]

42. Ma, X.; Cheng, Z.; Qin, R.; Qiu, Y.; Heng, Y.; Yang, H.; Ren, Y.; Wang, X.; Bi, J.; Ma, X.; et al. OsARG encodes an arginase that plays critical roles in panicle development and grain production in rice. Plant J. 2013, 73, 190-200. [CrossRef]

43. Murray, M.G.; Thompson, W.F. Rapid isolation of high molecular weight plant DNA. Nucleic Acids Res. 1980, 8, 4321-4325. [CrossRef]

44. Mjomba, F.M.; Zheng, Y.; Liu, H.; Tang, W.; Hong, Z.; Wang, F.; Wu, W. Homeobox is privotal for OsWUS controlling tiller development and female fertility in rice. G3 Genes Genom. Genet. 2016, 7, 2013-2021.

45. Xu, S.; Tao, Y.; Yang, Z.; Chu, J. A simple and rapid methods used for silver staining and gel preservation. Hereditas 2002, 24, 335-336. (In Chinese)

46. Lander, E.S.; Green, P.; Abrahamson, J.; Barlow, A.; Daly, M.J.; Lincoln, S.E.; Newburg, L. MAPMAKER: An interactive computer package for constructing primary genetic linkage maps of experimental and natural populations. Genomics 1987, 1, 174-181. [CrossRef] 